\title{
Two cases of perianal basal cell carcinoma
}

\section{Natsuko Matsumura, Kinuko Irie, Mai Endo, Takako Miura, Yasunobu Kato, Mikio Ohtsuka, Toshiyuki Yamamoto}

\author{
Department of Dermatology, Fukushima Medical University, Fukushima, Japan
}

Corresponding author: Dr. Natsuko Matsumura, E-mail: natsukom@fmu.ac.jp

Sir

Herein, we report two cases.

\section{CASE 1}

A 71-year-old female presented with a perianal mass seen for the past 10 years, growing slowly over 12 months prior to presentation. Her past medical history included primary biliary cirrhosis, dyslipidemia, gastroesophageal reflux disease, and osteoporosis. A dermatological examination revealed a reddish exophytic nodular lesion approx. $30 \times 25 \mathrm{~mm}$ in size in the perianal region at the 9 o'clock position (Fig. la). Aside from the perianal lesion, the anal canal was normal. A biopsy of the perianal region was performed, since the preliminary diagnosis was skin cancer, as squamous cell carcinoma or melanoma. The tumor was composed of a proliferation of basaloid cells with peripheral palisading in the dermis, and a mild mucin deposition was noted around the tumor (Figs. lb-ld). Histological findings revealed superficial basal cell carcinoma (BCC). The patient was referred to another hospital for further treatment.

\section{CASE 2}

An 80-year-old female presented with an itchy brownish lesion on the right side of the perianal region seen for the past year. She had a history of angina pectoris, uterine fibroid, and uterine prolapse. There was no medical history of radiotherapy, chemical exposure, or trauma to the genital area. There was no remarkable family history of skin disease or skin cancer. A physical examination revealed a single brownish patch with slight itching near the anus (Fig. 2a). Dermatoscopy showed a large bluish-gray ovoid nest, multiple bluishgray globules, and arborizing vessels (Fig. $2 \mathrm{~b}$ ). An incision biopsy was performed, showing basaloid cells with peripheral palisading in the superficial area of the dermis (Fig. 2c). The tumor was excised completely with a 2-4 mm clear margin. After the excision, there was no evidence of recurrence during a 3-month followup period.

Chronic exposure to the sun is a significant predisposing factor for BCC. More than $80 \%$ of BCC cases occur on sun-exposed areas, such as the head and neck [1]. Consequently, BCC of areas that are not sun-exposed, such as the axilla, nipple, or the genital and perianal areas, are extremely rare. It is estimated that perianal BCC accounts for only $0.08 \%$ of all BCCs [2]. In Japan, Hamada investigated 412 cases of BCC, and only 2 $(0.5 \%)$ perianal BCCs were identified. Nagamatsu reported $2(2.4 \%)$ BCCs located in the preanal area out of the 83 studied.

These regions are usually well covered and not exposed to sunlight. The etiologic factors for perianal BCC have not yet been clearly defined but, according to previous reports, the possible causes include radiation therapy, alternation in immune surveillance, exposure to coal tar or arsenic, sexually transmitted diseases, burns, traumatic scars, and chronic skin irritation $[3,4]$. Neither of our two cases had any of these etiologies. BCC occurs mainly in middle-aged and elderly patients, but the average age is slightly higher for perianal BCC, compared to the other types of BCC [5]. Moreover, most patients are men, and lesions are usually less than $2 \mathrm{~cm}$ in diameter [6]. Case 1 presented with a large ulcerated nodule $30 \times 25 \mathrm{~mm}$ in size. Case 2 presented with a hyperpigmented plaque with central ulceration. Our cases showed, thus, one nodular and

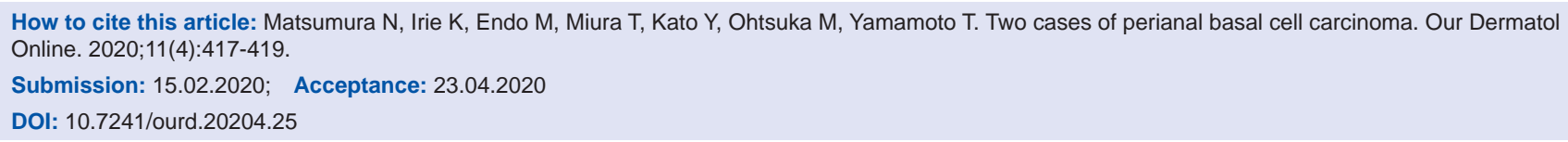




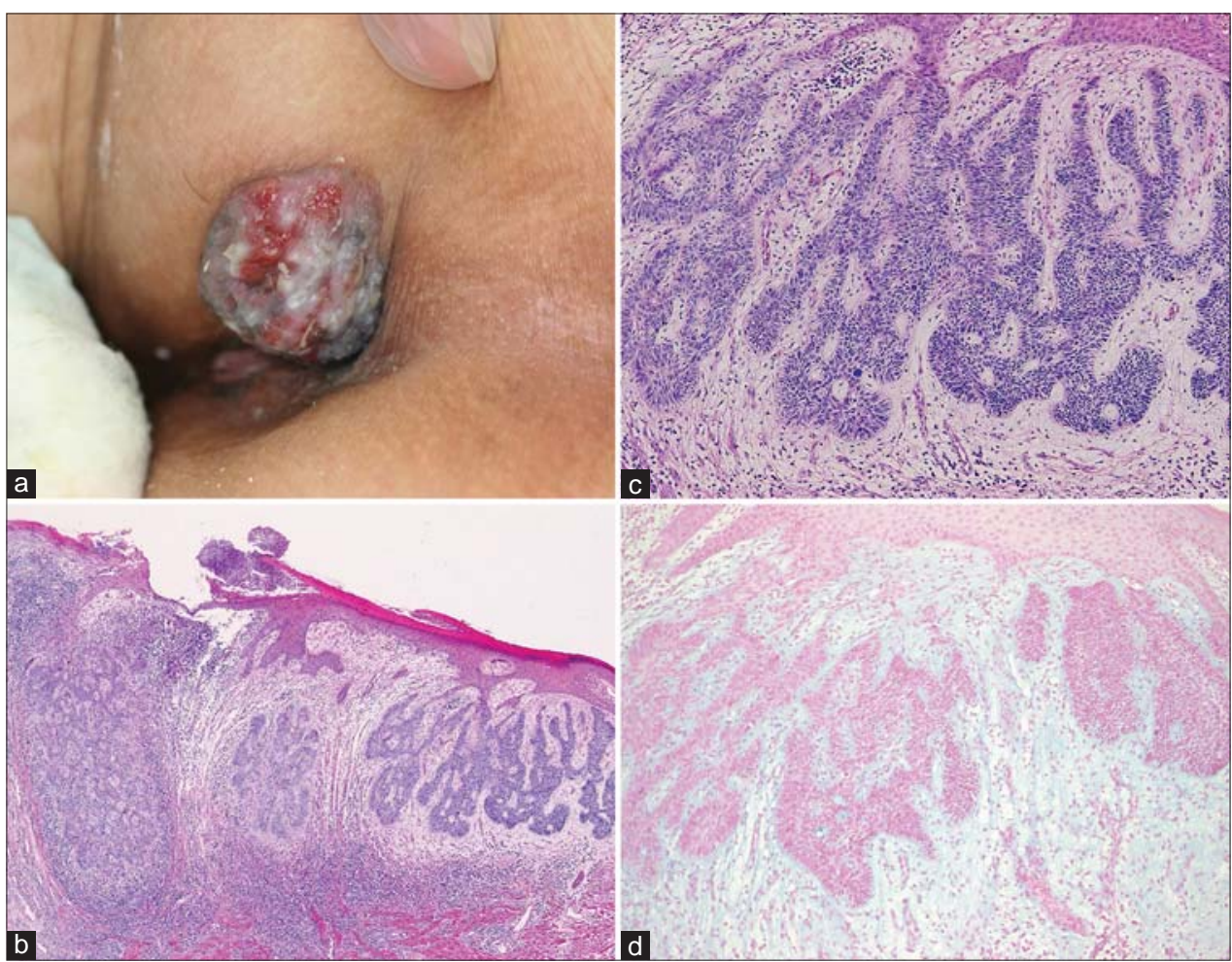

Figure 1: (a) A reddish exophytic nodular lesion approx. $30 \times 25 \mathrm{~mm}$ in size with central ulceration. (b) Anastomosing cords of basaloid cells connecting to the epidermis (H\&E, $\times 40)$. (c) A proliferation of basaloid cells with peripheral palisading in the dermis $(\mathrm{H} \& \mathrm{E}, \times 100)$. (d) Mucin pooling around the tumor. Alcian blue and colloidal iron stain positive around the peritumoral space.

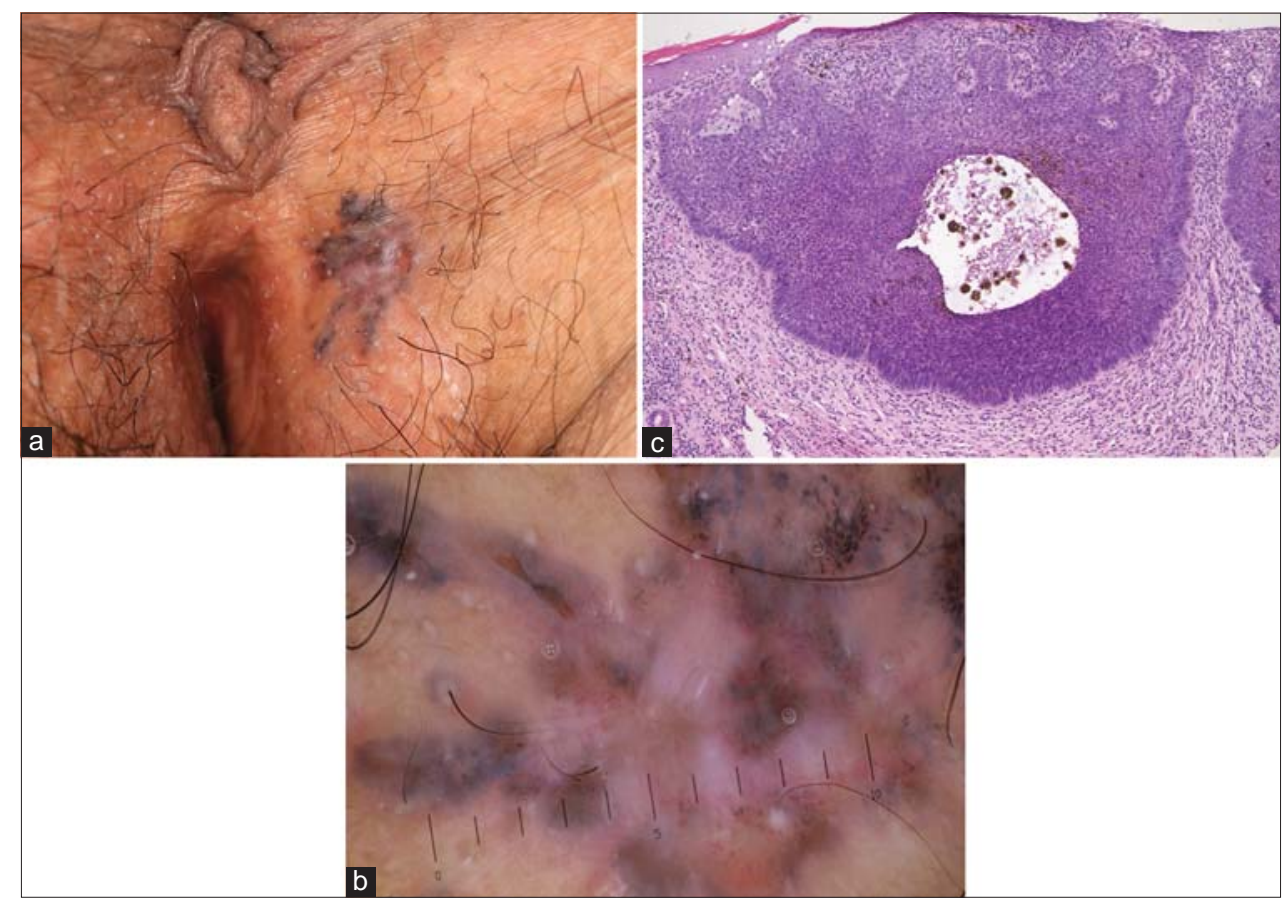

Figure 2: (a) A single brownish patch with slight itching near the anus. (b) A large bluish-gray ovoid nest, multiple bluish-gray globules, and arborizing vessels. (c) Basaloid cells with peripheral palisading in the superficial area of the dermis (H\&E, $\times 40)$.

one superficial BCC. A literature review revealed that the most common type of perianal BCC is nodular, followed by superficial [2].
According to the National Comprehensive Cancer Network (NCCN), a BCC in the perianal region is considered high-risk. Treatment options for 
perianal BCC include wide local excision and Mohs micrographic surgery. Case 2 was treated with a 2-4 $\mathrm{mm}$ excision with a clear margin, and no recurrence was observed during a 3-month follow-up period. A standard $4 \mathrm{~mm}$ margin excision should be considered in select tumors. In summary, because perianal BCC is so uncommon and the lesions are located in an inconspicuous area, Aldana insists that a biopsy should be considered for suspicious lesions in the perianal and genital areas [7]. Increased awareness of perianal BCC may contribute to the prevention of delayed diagnosis.

\section{Consent}

The examination of the patient was conducted according to the principles of the Declaration of Helsinki.

The authors certify that they have obtained all appropriate patient consent forms, in which the patients have given consent for images and other clinical information to be included in the journal. The patients understand that their names and initials will not be published and due effort will be made to conceal their identity, but that anonymity cannot be guaranteed.

\section{REFERENCES}

1 Park YJ, Kwon GH, Kim JO, Kim NK, Ryu WS, Lee KS. A retrospective study of changes in skin cancer characteristics over 11 years. Arch Craniofac Surg. 2020;21:87-91.

2 Aldana PC, Yfantis HG, John PR. perianal basal cell carcinoma successfully managed with excisional biopsy. Case Rep Dermatol Med. 2019;2019:6268354.

3 Bartos V. Development of multiple-lesion basal cell carcinoma of the skin: a comprehensive review. Sisli Etfal Hastan Tip Bul. 2019;53:323-8.

4 Zaouak A, Bouhajja L, Hammami H, Fenniche S. Giant basal cell carcinoma. Our Dermatol Online. 2020;11:92-3.

5 Otobe S, Ogaki J, Ishiwata K, Ohara K, Yoshino K. Two cases of perianal basal cell carcinoma. Rinsho Hifuka. 2016;58:1297-301.

6 Leonard D, Beddy D, Dozois EJ. Neoplasms of anal canal and perianal skin. neoplasms of anal canal and perianal skin. Clin Colon Rectal Surg. 2011;24:54-63.

7 Aldana PC, Yfantis HG, John PR. Perianal basal cell carcinoma successfully managed with excisional biopsy. Case Rep Dermatol Med. 2019;2019:6268354.

Copyright by Natsuko Matsumura, et al. This is an open access article distributed under the terms of the Creative Commons Attribution License, which permits unrestricted use, distribution, and reproduction in any medium, provided the original author and source are credited.

Source of Support: Nil, Conflict of Interest: None declared. 